\title{
ASPECTOS FÍSICO-QUÍMICOS E MICROBIOLÓGICOS DA ÁGUA DE CONSUMO DISPONÍVEL PARA A COMUNIDADE RURAL DE PATRIMÔNIO DOS PONCIANOS/MG
}

Physical, chemical and microbiological aspects of water consumption avaliable for the rual heritage Patrimônio dos Poncianos/MG Community

Aspectos físicos, químicos y microbiológicos del consumo de agua disponibles para la comunidad de Patrimônio dos Poncianos/MG

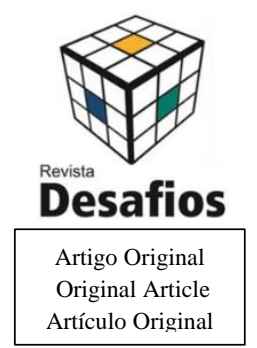

\author{
Wesley Cortes de Andrade ${ }^{1}$; Claudia Maria Tomás Melo ${ }^{2 *}$ \\ ${ }^{1}$ Mestre em Ciência e Tecnologia de Alimentos pelo Instituto Federal do Triângulo Mineiro, Uberaba, Brasil. \\ ${ }^{2}$ Docente do Instituto Federal do Triângulo Mineiro, Uberaba, Brasil.
}

*Correspondência: Instituto Federal do Triângulo Mineiro-Campus Uberlândia, Fazenda Sobradinho s/ $n^{o}$, Uberlândia, Minas Gerais, Brasil - CEP: 38400-970.email: claudiamelo@iftm.edu.br

Artigo recebido em 22/05/2020 aprovado em 18/08/2020 publicado em 31/10/2020.

\section{RESUMO}

Doenças de veiculação hídrica ainda é um desafio para o Ministério da Saúde, sendo a população rural a mais vulnerável em relação ao aparecimento destas doenças. O tratamento das águas naturais para abastecimento público consiste em adequar a água bruta aos parâmetros exigidos pela lei vigente estabelecida pela Portaria de Consolidação $\mathrm{n}^{\circ}$ 5, de 03 de outubro de 2017. Para verificar a qualidade da água no povoado de Patrimônio dos Poncianos/MG foram analisadas amostras de água de três pontos diferentes (P1, P2 e P3) em diferentes épocas: outubro e dezembro de 2018 e fevereiro de 2019, com intervalos de 45 dias entre cada coleta. A qualidade da água foi verificada através de análises físico-químicas e microbiológicas. Verificou-se que a maioria dos parâmetros analisados atenderam aos valores máximos permitidos estabelecidos pela Portaria $n^{\circ}$ 5. Entretanto, quanto aos parâmetros Nitrato, Turbidez e Coliformes Termotolerantes, estes não atenderam aos critérios de potabilidade. Em relação ao parâmetro Coliformes totais, independente do ponto de coleta da amostra e dos meses coletados, todas as amostras foram consideradas impróprias para o consumo humano, sugerindo-se tratamento da água, o que não foi observado no povoado.

Palavras-chave: análises químicas, comunidade rural, potabilidade.

\section{ABSTRACT}

Waterborne diseases are still a challenge for the Ministry of Health, with the rural population being the most vulnerable in relation to the appearance of these diseases. The treatment of natural waters for public supply consists of adapting raw water to the parameters required by the current law established by the Ordinance of Consolidation No. 5, of October 3rd, 2017. In order to check the quality of water in the village Patrimônio dos Poncianos/MG, water samples from three different places (P1, P2 and P3) were analyzed in different times: October and December 2018 and February 2019, with 45-day intervals between each collection. The quality of the water was verified through physical-chemical and microbiological analysis. It was found that most of the analyzed parameters met the maximum permitted values established by Ordinance No. 5. However, regarding the parameters Nitrate, Turbidity and Thermotolerant Coliforms, they did not meet the criteria for potability. Regarding the total coliform parameter, regardless of the place and the months the samples were collected, all samples were considered unsuitable for human consumption, suggesting the need for water treatment, which was not observed in the village.

Keywords: chemical analysis, rural community, potability. 


\section{RESUMEN}

Las enfermedades transmitidas por el agua siguen siendo un desafio para el Ministerio de Salud, siendo la población rural la más vulnerable en relación con la aparición de estas enfermedades. El tratamiento de las aguas naturales para el suministro público consiste en adaptar el agua cruda a los parámetros requeridos por la ley vigente establecida por la Ordenanza de Consolidación No. 5, del 3 de octubre de 2017. Para verificar la calidad del agua en el pueblo Patrimônio dos Poncianos / MG, las muestras de agua de tres lugares diferentes (P1, P2 y P3) se analizaron en diferentes momentos: octubre y diciembre de 2018 y febrero de 2019, con intervalos de 45 días entre cada colección. La calidad del agua se verificó mediante análisis físico-químicos y microbiológicos. Se encontró que la mayoría de los parámetros analizados cumplían con los valores máximos permitidos establecidos por la Ordenanza No. 5. Sin embargo, con respecto a los parámetros Nitrato, Turbidez y Coliformes Termotolerantes, no cumplían con los criterios de potabilidad. Con respecto al parámetro de coliformes totales, independientemente del lugar y los meses en que se recolectaron las muestras, todas las muestras se consideraron inadecuadas para el consumo humano, lo que sugiere la necesidad de tratamiento del agua, que no se observó en la aldea.

Descriptores: análisis químico, comunidad rural, potabilidad.

\section{INTRODUÇÃO}

\section{Qualidade da água}

Para Azevedo Netto (1990) somente 0,3\% da água no mundo pode ser aproveitada, sendo a maior parte subterrânea, e ainda assim não é própria para o consumo humano, já que existem impurezas contidas na mesma, fazendo-a passar por um processo de tratamento, para se adequar aos "padrões de potabilidade".

A água doce é um recurso natural, mas devido ao crescente aumento da população a sua qualidade vem piorando devido à ausência de políticas voltadas para a sua preservação.

Em 2010, a incidência de internações por doenças associadas à falta de saneamento tem sido 31,83 para cada 10 mil habitantes. Esse índice reduziu em anos posteriores, mas ainda não representa uma melhora significativa. No Brasil, em 2017 a incidência de internações por doenças associadas à falta de saneamento foi de 12,46 internações por $10 \mathrm{mil}$ habitantes (TRATA BRASIL, 2019).

Para Peçanha et al. (2012), o consumo de água de má qualidade pode causar graves impactos à saúde humana. Um deles são as infecções gastrointestinais, que causam óbito em aproximadamente 1,5 milhões de crianças no mundo, a maioria em países em desenvolvimento. Barcellos et al. (2006) reforçam este conceito relatando que a água é um elemento essencial para a vida, mas pela sua má qualidade pode trazer riscos à saúde, sendo um veículo para agentes químicos e biológicos.

Normalmente as contaminações da água de abastecimento se devem às más condições de saneamento básico, principalmente nas áreas rurais $\mathrm{e}$ subúrbios, onde estas atividades de saneamento são precárias, aumentando a prevalência de doenças transmitidas pela água, prejudicando o desenvolvimento físico e mental dos moradores (ARAÚJO et al., 2011).

A Portaria de Consolidação $\mathrm{n}^{\circ} 5$, de 03 de outubro de 2017 que revoga a antiga Portaria n ${ }^{\circ}$ 2.914, de 12 de dezembro de 2011, do Ministério da Saúde estabelece parâmetros físicos, químicos e microbiológicos que atendam os padrões vigentes de potabilidade (Tabela 01).

Para Bromberg (1995), o melhor método para obter boa segurança na qualidade da água para consumo consiste em evitar contaminação de fontes de 
água (rios, lagos e lagoas) por dejetos animais e humanos, que podem conter bactérias, vírus, protozoários e helmintos. Falhas na proteção dos corpos hídricos e no tratamento fazem com que a comunidade seja exposta a doenças infecciosas.

Tabela 01: Padrões de potabilidade de água para consumo humano permitidos pela legislação brasileira de acordo com a Portaria de Consolidação no 5, de 03 de outubro de 2017 do ministério da Saúde.

\begin{tabular}{ll}
\hline \multicolumn{1}{c}{ Parâmetro } & \multicolumn{1}{c}{$\begin{array}{c}\text { Valor Máximo Permitido } \\
\text { (VMP) }\end{array}$} \\
\hline $\mathrm{pH}$ & $6,0-9,0$ \\
Dureza & $500 \mathrm{mg} /{\mathrm{L} \mathrm{de} \mathrm{CaCO}_{3}}$ \\
Nitrato & $10,0 \mathrm{mg} / \mathrm{L} \mathrm{de} \mathrm{NO}^{-}$ \\
Cloretos & $250 \mathrm{mg} / \mathrm{L} \mathrm{de} \mathrm{Cl}^{-}$ \\
Alcalinidade & $400 \mathrm{mg} / \mathrm{L} \mathrm{CaCO}_{3}$ \\
Turbidez & $5 \mathrm{UNT}($ Unidade de Turbidez) \\
Cor & $15 \mathrm{uH}$ (Unidade Hazen \\
Oxigênio & $>6 \mathrm{mg} / \mathrm{L}$ \\
dissolvido (OD) & \\
Coliformes totais & Ausência em $100 \mathrm{~mL}$ \\
Coliformes & Ausência em $100 \mathrm{~mL}$ \\
termotolerantes & \\
Escherichia coli & Ausência em $100 \mathrm{~mL}$ \\
\hline
\end{tabular}

Fonte: BRASIL, 2017 (adaptado).

\section{Características da água}

\section{Características Físicas}

São chamadas de características físicas da água: turbidez, sólidos solúveis e insolúveis, cor, odor, sabor, temperatura e $\mathrm{pH}$, porque podem impressionar os sentidos (visão, olfato e paladar) (MARTEL, 2004).

Segundo Pavanelli (2001), as principais características físicas da água é a turbidez e a cor. Para Di Bernardo e Dantas (2005), as principais são: cor, turbidez, sabor, odor, temperatura e condutividade elétrica (CE).

Segundo Tominaga e Mídio (1999), águas naturais podem conter grande quantidade de matéria orgânica como carboidratos, proteínas, óleos e graxas e compostos sintéticos como detergentes, pesticidas e fenóis, que podem reagir com o cloro livre e formar diversos subprodutos denominados de trialometanos, que são muito tóxicos e cancerígenos ao ser humano, e, devido a esta reação, quando a quantidade de compostos orgânicos for elevada, não se aconselha fazer a cloração da água.

A cloração é um dos métodos mais utilizados e com maior viabilidade nas estações de tratamento de água, consistindo na última etapa de tratamento. Esta etapa é responsável pela desinfecção da água para seguir assim para a distribuição aos domicílios (SILVA, 2017).

\section{Características biológicas}

Para analisar as características biológicas das águas normalmente são realizadas análises bacteriológicas e hidrobiológicas (DI BERNARDO; DANTAS, 2005).

Segundo Brasil (2004) a água distribuída para consumo humano deve estar livre de qualquer contaminação, seja ela, de origem química, física ou microbiológica, não devendo de maneira alguma oferecer risco à saúde humana.

Os microrganismos, como os grupos dos coliformes, não residem naturalmente na água, eles são introduzidos ao meio por dejetos de pessoas, como por exemplo, material fecal, afetando o ser humano por meio de ingestão ou contato com água contaminada (PAULA, 2008).

Coliformes totais e termotolerantes são os indicadores de poluição por fezes, pois quanto maior a quantidade de coliformes encontrado na água, mais alta será a chance da existência de patógenos (DI BERNARDO; DANTAS, 2005).

Para Franco e Landgraf (1996) a Escherichia coli é uma espécie de bactéria que pode ser dividida em cinco grupos: enterotoxigênicas, enteropatogênicas, enteroinvasivas, enterohemorrágicas e enteroagregativas. 


\section{Disponibilidade de água}

O Brasil é um dos países mais privilegiados por possuir grande disponibilidade hídrica, que corresponde cerca de $12 \%$ da água doce no mundo (BRASIL, 2010).

Para Esteves (2012), estima-se que o Brasil possui de $12 \%$ a $16 \%$ do volume total de água do planeta, sendo que no norte do país existe disponibilidade de $73 \%$ de água, enquanto os $27 \%$ restantes dividem-se entre as outras regiões.

Segundo a Unesco (2015) a previsão em 2050 é que a população mundial seja de 10 bilhões de habitantes. Se forem mantidas as condições atuais de abastecimento de água e distribuição, $70 \%$ da população mundial enfrentarão deficiência de água, e 1/4 viverá escassez de água potável.

A disponibilidade da água, juntamente com a sua qualidade, é cada vez mais preocupante à medida que a atividade agrícola e industrial se expande e a população humana cresce desenfreadamente (ONU, 2010).

\section{Abastecimento de água para populações rurais}

Para UNICEF (1999), um dos principais fatores pela falta de abastecimento e saneamento básico em zonas rurais é a dificuldade de implementação de tubulações da estação de tratamento até as áreas rurais, devido a maior distância, o que acarreta custos mais elevados do que em zonas urbanas.

Segundo Casali (2008), a implantação de inovações tecnológicas de captação e tratamento da água é um fator limitante para toda população, principalmente da zona rural. Isto se justifica, pois, grandes centros urbanos, em sua maioria, ainda não dispõem de tratamento adequado para água, apresentando somente tratamento simplificado. Há grande dificuldade no monitoramento constante da qualidade da água, pois muitas vezes o esgoto não é tratado, principalmente nos pequenos povoados, podendo ser descartado próximos aos mananciais, causando poluições.

Para Brito, Amorim e Leite (2007), os serviços de abastecimento de água e tratamento para a população rural são bem precários em relação aos centros urbanos.

$\mathrm{Na}$ prática, o abastecimento de água para a população da zona rural é diferente da urbana, visto que as principais fontes de abastecimento e captação do meio rural se dão por poços rasos, poços artesianos, nascentes, córregos e rios, que se encontram na região, não tendo na sua maioria uma fiscalização correta, constituindo-se de contaminação (FERREIRA et al., 2017).

O abastecimento de água do meio rural é crítico, visto que não é abastecida por empresas de saneamento e sua água vem de poços, mananciais e rios alternativos, não recebendo os tratamentos físicoquímicos e microbiológicos adequados (CASALI, 2008). Para Silva et al. (2009) moradores acabam tendo o principal papel de garantir a qualidade da água que consomem, dando atenção as tubulações e reservatórios por onde passa sua própria água, adotando práticas de higiene domiciliares e não práticas padrões.

O melhor método de tratamento de água de abastecimento de pequenas populações, em situações em que a água disponível para beber não ofereça confiança, principalmente em períodos que tenha ocorrido algum surto de epidemias, é o método de fervura da água, sendo uma aplicação mais barata para a população, principalmente da zona rural (PINTO; ARAÚJO; SILVA JÚNIOR, 2015).

Baseado no fato de que muitos municípios brasileiros, principalmente as comunidades rurais, não apresentam nenhuma forma de tratamento de suas águas e que os despejos domésticos ocorrem de forma inadequada, este trabalho teve como objetivo avaliar a 
qualidade físico-química e microbiológica da água de consumo da Comunidade Patrimônio dos Poncianos/MG.

\section{METODOLOGIA}

\section{Local de Estudo: Comunidade Patrimônio dos Poncianos}

A comunidade Patrimônio dos Ponciano, localiza-se na zona rural cerca de $33 \mathrm{~km}$ da cidade de Conceição das Alagoas/MG (1953'10.5”S $\left.48^{\circ} 12^{\prime} 28.4^{\prime \prime} \mathrm{W}\right)$, conforme Figuras 01 e 02.

Figura 01. Mapa da localização da comunidade Patrimônio dos Ponciano/MG.

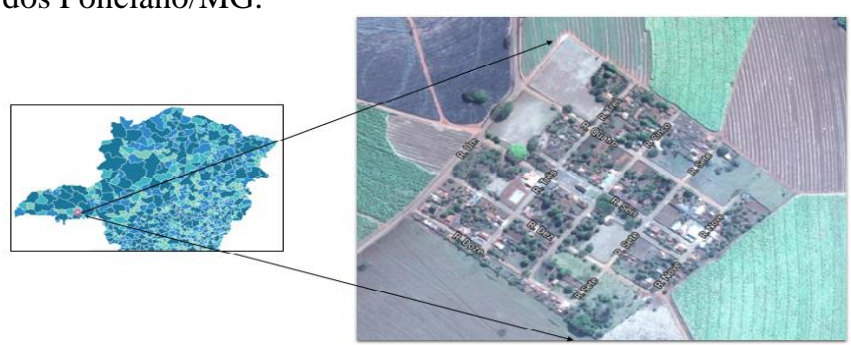

Fonte: Google Earth, 2017 (Adaptado); IBGE, 2010.

Figura 02. Área da comunidade rural.

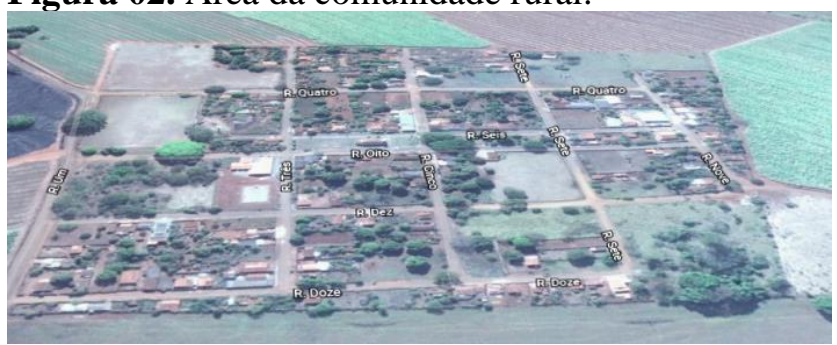

Fonte: Google Earth, 2017 (Adaptado)

De acordo com o Instituto Brasileiro de Geografia e Estatística - IBGE (2010), a população da cidade de Conceição das Alagoas é 23.043 habitantes, sendo 20.880 na área urbana e 2.163 na zona rural. A comunidade rural de Patrimônio dos Poncianos possui aproximadamente 350 habitantes, com uma faixa territorial de $1352,2 \mathrm{~km}^{2}$.

Patrimônio dos Poncianos era uma comunidade quilombola, que foi transformada em um bairro rural da cidade de Conceição das Alagoas.
A economia da região era dominada pelo garimpo, mas com o esgotamento de pedras preciosas a fabricação manual de cerâmicas ganhou forças, e, além dessas oficinas de olarias a pecuária de leite e corte e os plantios de grãos passaram a ser base da economia. Atualmente o plantio de cana de açúcar é a grande base da atividade econômica da região (CONCEIÇÃO DAS ALAGOAS, 2018).

Atualmente a comunidade de Patrimônio dos Ponciano/MG é abastecida por água subterrânea para uso em suas atividades domésticas.

\section{Caracterização de amostras de água da comunidade dos Poncianos/ MG}

A coleta de amostras de água foi realizada no segundo semestre de 2018 e no primeiro semestre de 2019, através de visitas feitas no local do estudo. As torneiras estavam situadas na zona rural do município de Conceição das Alagoas-MG, na comunidade rural do Patrimônio dos Poncianos, sendo o Ponto 1 (P1) localizado à $19^{\circ} 88^{\prime} 57.2^{\prime \prime}$ S $48^{\circ} 20^{\prime} 90.6^{\prime \prime} \mathrm{W}$, o Ponto 2 (P2) localizado à $19^{\circ} 88^{\prime} 62.1^{\prime \prime} \mathrm{S} 78^{\circ} 20^{\prime} 81.6^{\prime \prime} \mathrm{W}$, e o Ponto 3 (P3) localizado à 1988'66.8”'S 48²0'75.7”'W (Figura 03 e 04). As torneiras eram abastecidas por uma única caixa d'água e por um único poço de água subterrâneo (Figura 05). A água, portanto, era proveniente de uma mesma captação subterrânea. As análises foram realizadas em triplicata, com seis repetições, sendo as coletas realizadas quinzenalmente, e os resultados foram submetidos ao tratamento estatístico, pelo teste de Tukey, gerando um comparativo entre as médias pelo software Agroestat. 
Figura 03. Localização dos Pontos de Coletas

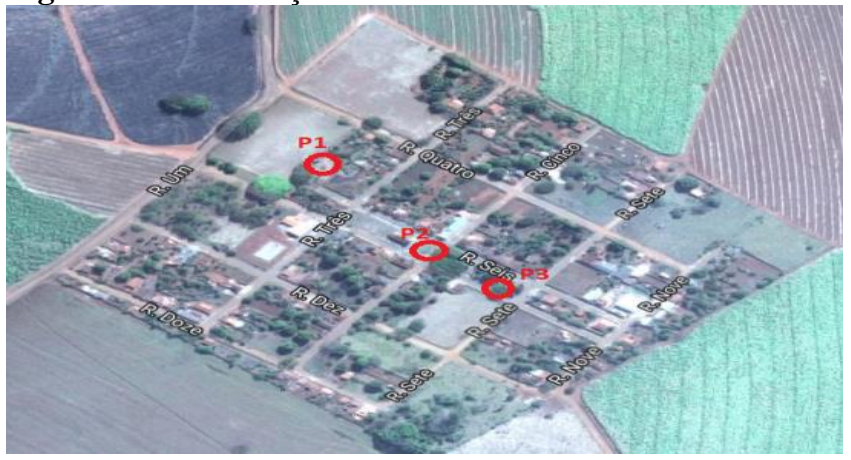

Fonte: Google Earth (2018).

As amostras foram coletadas seguindo as orientações de acondicionamento e armazenamento da FUNASA (2006).

Figura 04. Localização dos Pontos de Coleta.

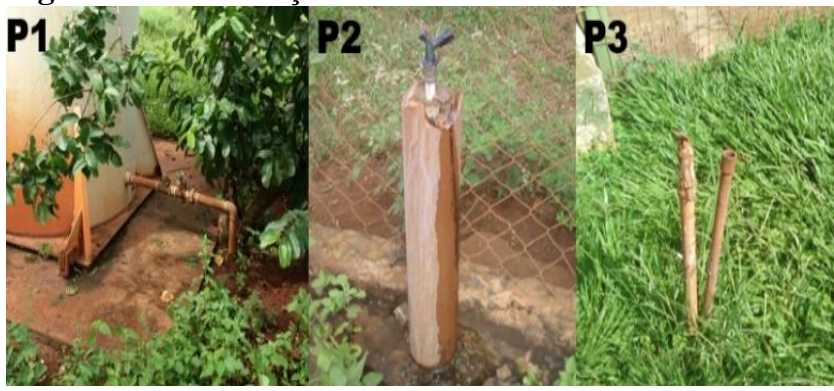

Fonte: Autor.

Figura 05. Caixa d'água para abastecimento da comunidade por fonte de água subterrânea.

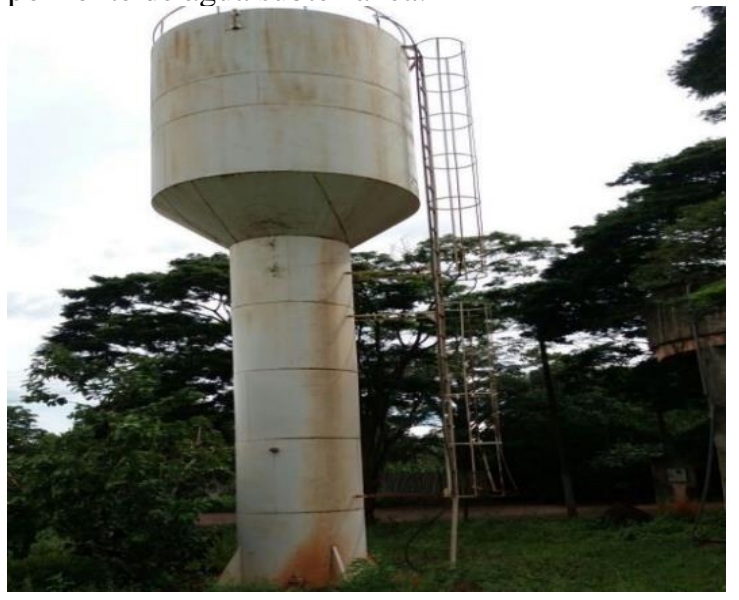

Fonte: Autor

\section{Procedimento experimental de análise da água}

As amostras foram submetidas a análises físico-químicas e microbiológicas descritas nas Tabelas 02 e 03 com os seus respectivos métodos, de acordo com o APHA (2005) e Instituto Adolfo Lutz (2008), processadas no Laboratório de Química e
Microbiologia, ambos pertencentes ao Instituto Federal do Triângulo Mineiro-Campus Uberaba, sendo os resultados obtidos comparados com a legislação vigente.

Tabela 02. Método dos Parâmetros físico-químicos

\begin{tabular}{ll}
\hline Parâmetro & Método \\
\hline Cloretos & Titulométrico \\
Condutividade & Condutivimétrico \\
elétrica & \\
Dureza & Titulométrico \\
Nitrato & Espectrofotométrico \\
pH & Potenciométrico \\
Salinidade (CE) & Condutivimétrico \\
Turbidez & Turbidimétrico \\
\hline
\end{tabular}

Fonte: APHA (2005) e INSTITUTO ADOLFO LUTZ (2008).

Tabela 03. Método dos Parâmetros Microbiológicos

\begin{tabular}{ll}
\hline Parâmetro & Método \\
\hline Coliformes Totais & Tubos Múltiplos \\
Coliformes & Tubos Múltiplos \\
Termotolerantes & \\
\hline
\end{tabular}

Fonte: APHA (2005) e INSTITUTO ADOLFO LUTZ (2008).

\section{Análise estatística dos dados experimentais}

Para o tratamento dos dados das análises físico-químicas da água de abastecimento foi utilizado o software Estatística AgroEstat. Os resultados foram avaliados através de análise de variância e teste de média de Tuckey. O nível de significância de 5\% foi considerado. Para as análises microbiológica foi observado o resultado médio das amostras e comparado com legislação vigente.

\section{RESULTADOS E DISCUSSÃO}

\section{Análises físico e químicas de amostras de água}

A Tabela 4 apresenta o valor médio dos parâmetros pH, cloretos, dureza, nitratos, condutividade elétrica, turbidez e salinidade das amostras de água de cada ponto analisado, comparando com os valores máximos permitidos (VMP) pela portaria de Consolidação MS nº 5/2017 
(Tabela 01), que dispõe sobre os procedimentos de controle e de vigilância da qualidade da água para consumo humano, juntamente com o seu padrão de potabilidade.

Em relação aos valores de $\mathrm{pH}$ apresentados na Tabela 4, apenas o do mês de dezembro ( $2^{\circ}$ Coleta) não se enquadra nos padrões que são estabelecidos pela normativa, que recomenda um $\mathrm{pH}$ entre 6,0 a 9,0.

Os resultados médios das análises de cloretos, salinidade e condutividade elétrica (CE) (Tabela 4) apresentaram as maiores médias na $3^{\mathrm{a}}$ coleta, mês de fevereiro, seguida do mês de dezembro. As menores médias para os valores destes três parâmetros foram obtidas em amostras coletadas no mês de outubro. Em relação aos pontos de coleta, não houve diferença significativa $(\mathrm{p}<0,05)$ entre eles, independentemente do período de coleta das amostras.

De acordo com a Portaria de Consolidação MS $n^{\circ} 5 / 2017$, os valores de cloretos apresentados enquadram-se nos padrões estabelecidos pela norma, a qual recomenda um valor máximo permitido de 250 $\mathrm{mg} / \mathrm{L}$ de cloretos, mas esta portaria não estipula valor máximo permitido de condutividade elétrica para água potável, no entanto, de acordo com Coelho (2017) a condutividade média de grande parte das águas doces variam entre 10 a $1.000 \mathrm{mS} / \mathrm{cm}$, sendo assim, os resultados obtidos nesta pesquisa se enquadram dentro dos valores mencionados pelo referido autor.

Como a condutividade elétrica mede os íons dissolvidos na água, verifica-se que estes valores são diferentes em diferentes localidades pois os sais que se solubilizam e que estão presentes no solo são características intrínsecas de cada região.

Em relação ao parâmetro salinidade, os resultados obtidos neste estudo, realizando a conversão de unidades para partes por mil, tem-se que os valores variaram de 0,73 a $1,11 \%$, sendo a água analisada classificada, segundo CONAMA
N³57/2005, como água salobra, águas com salinidade de 0,5 -30\% (partes por mil).

A concentração de nitratos $\left(\mathrm{mg} . \mathrm{L}^{-1}\right)$ na primeira coleta (mês de outubro), apresentou uma média de 11,33 mg/L, sendo que não houve diferença significativa de nitratos independente do ponto de coleta. Nas duas últimas coletas, realizadas nos meses de dezembro e fevereiro, o mesmo foi verificado, mas houve redução da média de nitratos nas amostras avaliadas, 9,55 mg. $\mathrm{L}^{-1}$ e $8,80 \mathrm{mg} . \mathrm{L}^{-1}$, respectivamente. Esta diferença do resultado no mês de outubro com as demais coletas, provavelmente se deve ao periodo chuvoso, que possivelmente sofreu influência da lixiviação, oriunda de esgotos ou aplicação de fertilizantes, elevando assim o índice de nitratos neste período, que, comparado com a legislação vigente, não se enquandra dentro do limite máximo permitido que é de $10 \mathrm{mg} . \mathrm{L}^{-1}$ de nitrato. Neste caso, a fonte de água, não seria segura para o consumo humano.

Foi verificado as maiores médias de turbidez no mês de fevereiro, 5,70 NTU, e outubro 5,35 NTU, sendo que estes resultados não se enquadram nos padrões estabelecidos pela normativa brasileira.

Todos os resultados das análises de dureza, independentemente do tempo e do local da coleta se enquadraram dentro dos limites estabelecidos pela legislação vigente.

\section{Análise microbiológica}

O padrão de potabilidade para água destinada ao consumo humano, segundo a Portaria de Consolidação MS n 5/2017, estabelece ausência de coliformes totais em $100 \mathrm{~mL}$ de amostra. Assim, mediante os resultados apresentados na Tabela 05 foi possível observar que os três pontos de estudo (P1, P2 e P3) não atenderam aos padrões de potabilidade. 
Tabela 05: Valores médios de Coliformes Totais de amostras de água

\begin{tabular}{lllll}
$\begin{array}{l}\text { C.Totais T } \\
\text { (NMP/100 mL) }\end{array}$ & $\mathbf{1}^{\mathbf{o}}$ & $\mathbf{2}^{\mathbf{o}}$ & $\mathbf{3}^{\mathbf{0}}$ & VMP \\
\hline P1 & 23 & 1,1 & 2,2 & A\# \\
P2 & 23 & 1,1 & 1,65 & A\# \\
P3 & 23 & 1,1 & 1,1 & A\# \\
\hline
\end{tabular}

A\#: ausente Fonte: Elaborado pelo autor; *NMP: Número Mais Provável.

Os resultados das análises estão em concordância com trabalho desenvolvido por Silva (2017), que ao analisar água de poços localizados na zona rural da cidade de Caruaru-PE, obteve resultados entre 27 NMP/100 mL e $1600 \mathrm{NMP} / 100 \mathrm{~mL}$, valores acima do estabelecido pela portaria MS n ${ }^{\circ}$ 5/2017.

Para Von Sperling (2005) este grupo de Coliformes é devido a águas e solos poluídos com dejetos de humanos e de animais de sangue quente. Desta forma sugere-se que a possível contaminação das águas analisadas é devido à presença de fezes dos animais presentes na área do entorno, levando em conta também a falta de saneamento básico da comunidade.

A presença de coliformes totais nas amostras das águas dos poços não é, necessariamente, um indicativo de presença de Coliformes Termotolerantes, conforme é apresentado na (Tabela 05), podendo ser utilizada como um indicador ambiental, representando apenas bactérias de vida livre e não intestinal.

Tabela 06: Valores médios de Coliformes Termotolerantes em amostras de água

\begin{tabular}{lllll}
\hline $\begin{array}{l}\text { C.Termotolerantes } \\
\text { (NMP/100 mL) }\end{array}$ & $\begin{array}{l}\mathbf{1}^{\mathbf{o}} \\
\text { coleta }\end{array}$ & $\begin{array}{l}\mathbf{2}^{\mathbf{o}} \\
\text { coleta }\end{array}$ & $\begin{array}{l}\mathbf{3}^{\text {o }} \\
\text { coleta }\end{array}$ & VMP \\
\hline P1 & 2,9 & A\# & A\# & A\# \\
P2 & 6 & A\# & A\# & A\# \\
P3 & 6,9 & A\# & A\# & A\# \\
\hline
\end{tabular}

A\#: ausente Fonte: Elaborado pelo autor; *NMP: Número Mais Provável.

Tabela 04: Parâmetros físico e químicos analisados na Comunidade de Patrímônio dos Poncianos MG, em 3 coletas realizadas no ponto $\mathrm{P} 1, \mathrm{P} 2$ e $\mathrm{P} 3$

\begin{tabular}{|c|c|c|c|c|c|}
\hline Parâmetro & & $1^{a}$ coleta & $2^{\mathbf{a}}$ coleta & $3^{a}$ coleta & VMP \\
\hline \multirow{3}{*}{$\mathrm{pH}$} & $\mathrm{P} 1$ & $7,20 \pm 0,062 \mathrm{Bb}$ & $9,72 \pm 0,060 \mathrm{Aa}$ & $7,87 \pm 0,298 \mathrm{Ab}$ & \multirow{3}{*}{$6-9$} \\
\hline & $\mathrm{P} 2$ & $7,35 \pm 0,058 \mathrm{Ac}$ & $9,87 \pm 0,054 \mathrm{Aa}$ & $8,00 \pm 0,111 \mathrm{Ab}$ & \\
\hline & P3 & $7,39 \pm 0,021 \mathrm{Ac}$ & $9,85 \pm 0,055 \mathrm{Aa}$ & $8,02 \pm 0,105 \mathrm{Ab}$ & \\
\hline \multirow{4}{*}{ Cloretos $\left(\mathrm{mg} \mathrm{L}^{-1}\right)$} & $\mathrm{P} 1$ & $0,80 \pm 0,041 \mathrm{Ac}$ & $2,91 \pm 0,094 \mathrm{Ab}$ & $3,79 \pm 0,257 \mathrm{Aa}$ & \multirow{3}{*}{250} \\
\hline & $\mathrm{P} 2$ & $0,81 \pm 0,030 \mathrm{Ac}$ & $3,09 \pm 0,044 \mathrm{Ab}$ & $3,93 \pm 0,141 \mathrm{Aa}$ & \\
\hline & P3 & $0,83 \pm 0,038 \mathrm{Ac}$ & $3,13 \pm 0,115 \mathrm{Ab}$ & $4,05 \pm 0,107 \mathrm{Aa}$ & \\
\hline & $\mathrm{P} 1$ & $76,20 \pm 0,253 \mathrm{Bc}$ & $80,10 \pm 0,068 \mathrm{Ab}$ & $82,05 \pm 0,176 \mathrm{Aa}$ & \multirow{3}{*}{500} \\
\hline \multirow[t]{3}{*}{ Dureza $\left(\mathrm{mg} \mathrm{L}^{-1}\right)$} & $\mathrm{P} 2$ & $77,90 \pm 0,108 \mathrm{Ac}$ & $80,21 \pm 0,038 \mathrm{Ab}$ & $82,03 \pm 0,160 \mathrm{Aa}$ & \\
\hline & P3 & $77,94 \pm 0,039 \mathrm{Ac}$ & $80,27 \pm 0,083 \mathrm{Ab}$ & $82,02 \pm 0,149 \mathrm{Aa}$ & \\
\hline & $\mathrm{P} 1$ & $11,33 \pm 0,064 \mathrm{Aa}$ & $9,45 \pm 0,084 \mathrm{Ab}$ & $8,59 \pm 0,150 \mathrm{Ab}$ & \multirow{3}{*}{10} \\
\hline \multirow[t]{3}{*}{ Nitratos $\left(\mathrm{mg} \mathrm{L}^{-1}\right)$} & $\mathrm{P} 2$ & $11,31 \pm 0,052 \mathrm{Aa}$ & $9,54 \pm 0,052 \mathrm{Ab}$ & $8,85 \pm 0,107 \mathrm{Ac}$ & \\
\hline & P3 & $11,35 \pm 0,045 \mathrm{Aa}$ & $9,67 \pm 0,149 \mathrm{Ab}$ & $8,98 \pm 0,101 \mathrm{Ac}$ & \\
\hline & $\mathrm{P} 1$ & $151,85 \pm 0,197 \mathrm{Ac}$ & $199,98 \pm 0,061 \mathrm{Ab}$ & $221,28 \pm 0,872 \mathrm{Aa}$ & \multirow{3}{*}{-} \\
\hline \multirow[t]{2}{*}{$\mathrm{CE}\left(\mu \mathrm{s} . \mathrm{cm}^{-1}\right)$} & $\mathrm{P} 2$ & $151,81 \pm 0,027 \mathrm{Ac}$ & $200,15 \pm 0,045 \mathrm{Ab}$ & $222,45 \pm 0,300 \mathrm{Aa}$ & \\
\hline & P3 & $151,94 \pm 0,060 \mathrm{Ac}$ & $200,21 \pm 0,066 \mathrm{Ab}$ & $222,20 \pm 0,096 \mathrm{Aa}$ & \\
\hline \multirow{3}{*}{ Turbidez (NTU) } & P1 & $5,28 \pm 0,059 \mathrm{Ab}$ & $0,27 \pm 0,037 \mathrm{Ac}$ & $5,42 \pm 0,319 \mathrm{Aa}$ & \multirow{3}{*}{5} \\
\hline & $\mathrm{P} 2$ & $5,28 \pm 0,051 \mathrm{Ab}$ & $0,42 \pm 0,058 \mathrm{Ac}$ & $5,88 \pm 0,060 \mathrm{Aa}$ & \\
\hline & P3 & $5,50 \pm 0,034 \mathrm{Ab}$ & $0,47 \pm 0,053 \mathrm{Ac}$ & $5,79 \pm 0,192 \mathrm{~A}$ & \\
\hline \multirow{3}{*}{ Salinidade (psu) } & $\mathrm{P} 1$ & $110,10 \pm 0,16 \mathrm{Ac}$ & $148,55 \pm 0,05 \mathrm{Ab}$ & $165,84 \pm 0,71 \mathrm{Aa}$ & \multirow{3}{*}{-} \\
\hline & $\mathrm{P} 2$ & $110,07 \pm 0,02 \mathrm{Ac}$ & $148,69 \pm 0,04 \mathrm{Ab}$ & $166,80 \pm 0,24 \mathrm{Aa}$ & \\
\hline & P3 & $110,17 \pm 0,05 \mathrm{Ac}$ & $148,72 \pm 0,05 \mathrm{Ab}$ & $166,59 \pm 0,08 \mathrm{Aa}$ & \\
\hline
\end{tabular}

As médias seguidas de mesma letra minúscula na coluna não diferem quanto ao ponto de coleta e letras maiúsculas na linha não diferem em relação às coletas realizadas, pelo teste de Tukey a 5\%. 
A Portaria de Consolidação MS n $n^{\circ}$ /2017 estabelece ausência de coliformes termotolerantes em $100 \mathrm{~mL}$ de amostras e verifica-se, pelos resultados apresentados na Tabela 06, que durante o mês de outubro as fontes de água não atenderam aos padrões de potabilidade, embora nos meses dezembro e fevereiro, independente dos pontos de coletas, as amostras de água atenderam aos requisitos da legislação vigente. Ramos e Barroso (2014), ao analisaram a qualidade da água de poços na localidade de Donana (Campos dos Goytacazes) encontraram $33 \%$ das amostras contaminadas por coliformes termotolerantes, um resultado superior ao encontrado neste estudo, mostrando que muitas fontes de água estão contaminadas e são impróprias para uso doméstico, sem tratamento prévio.

Vários pesquisadores (Patias et al. (2016); Sousa et al. (2019); Cabral e Araújo (2016); Bortoli et al. (2017); Zerwes et al. (2015)) têm avaliado a qualidade da água de comunidades rurais de diferentes regiões do Brasil e a maioria deles têm verificado que a água que serve estas comunidades não atende aos padrões de potabilidade estabelecido pela normativa Brasileira.

\section{CONCLUSÃO}

Em termos de potabilidade, considerando portaria MS 05/2017, parte dos parâmetros analisados atenderam aos valores máximos permitidos estabelecidos pela normativa, entretanto, os parâmetros de Nitrato, Turbidez e Coliformes Termotolerantes não atenderam aos critérios de potabilidade. No mês de fevereiro, o parâmetro Turbidez, também não atendeu aos critérios exigidos pela normativa.

Em relação ao parâmetro Coliformes totais, independente do ponto de coleta da amostra e dos meses coletados, todas as fontes foram consideradas imprópria para o consumo humano, sugerindo-se assim necessidade de tratamento da água para distribuição à população.

Verificou-se através da pesquisa realizada que as políticas de saúde pública da comunidade não têm alcançado satisfatoriamente os objetivos de melhoria dos indicadores sanitários e para isto é necessário, no mínimo, a cloração da água e a realização de análises físico-químicas e microbiológicas. As análises devem ser realizadas pelo menos uma vez por semana até a implantação de análises diárias. Com os resultados das análises é possível verificar a eficiência da cloração e, consequentemente, a qualidade da água disponível para a comunidade Patrimônio dos Poncianos. Outras condutas importantes a serem implantadas pela administração pública seria implantação de projetos de Educação ambiental e criação de locais específicos para o descarte de resíduos domésticos. 


\section{AGRADECIMENTO}

Os autores agradecem ao Instituto Federal de Ciência e Tecnologia do Triângulo Mineiro, e à FAPEMIG pelo apoio à pesquisa e à professora Elisa Norberto Ferreira Santos pelo auxílio no tratamento estatístico dos dados experimentais.

Todos os autores declararam não haver qualquer potencial conflito de interesses referente a este artigo.

\section{REFERÊNCIAS}

APHA/AWWA/WEF. EATON, A.D.; et al. Standard methods for the examination of water and wastewater. $21^{\mathrm{a}}$ ed. Washington: American Public Health Association. 1082 p. 2005.

ARAÚJO, H. M. C.; MONTEBELLO, N. di P.; BOTELHO, R. B. A.; ZANDONADI, R. P.; AKUTSU, R. de C.; GINANI, V. C. Métodos e indicadores culinários. In: ARAÚJO, W. M. C. et al. Alquimiados alimentos. 2. Ed. Brasília: Editora Senac-DF, cap. 5 (p. 167 - 196), 2011.

AZEVEDO NETTO - Curso de treinamento à distância- Captação de Água Subterrânea Cap.1Companhia de Tecnologia de Saneamento AmbientalCETESB/SP, 1990.

BARCELLOS, C. M.; ROCHA, M.; RODRIGUES, L. S.; COSTA, C. C.; OLIVEIRA, P. R.; SILVA, I. J.; JESUS, E. F. M.; ROLIM, R. G. Avaliação da qualidade da água e percepção higiênico-sanitária na área rural de Lavras. Minas Gerais, Brasil, 1999-2000. Cadernos de Saúde Pública, Rio de Janeiro, 22(9):1967-1978, set, 2006.

BORTOLI, J.; REMPEL, C.; MACIEL, M.J.; SALVI., L.C. Qualidade físico-química da água em propriedades rurais com produção de leite no Vale do Taquari-RS RS. Caderno Prudentino de Geografia, Presidente Prudente, n. 39 v. 1, p. 81-102, jan./jun., 2017

BRASIL. AGÊNCIA NACIONAL DE ÁGUAS. Atlas Brasil: abastecimento urbano da água: panorama nacional. Brasília: Ana, Engecorps, Cobrape, 2010. Disponível em: $<$ http://atlas.ana.gov.br/Atlas/downloads/atlas/Resum o\%20Executivo/Atlas\%20Brasi1\%20-

$\% 20$ Volume $\% 201 \% 20$ -

$\% 20$ Panorama\%20Nacional.pdf >. Acesso: 03 dez. 2017.
BRASIL. Portaria de Consolidação $\mathbf{n}^{0} 05$, de 03 de outubro de 2017. Estabelece os procedimentos e responsabilidades relativos ao controle e vigilância da qualidade da água para consumo humano e seu padrão de potabilidade. Ministério da Saúde, Brasília, série E, 2017. Publicação No 190 - DOU de 03/10/17 - Seção 1 - Suplemento. p.360.

BRASIL. Ministério da Saúde. Portaria n ${ }^{\circ}$ 518, de 25 de março de 2004. Legislação em vigilância sanitária. Estabelece os procedimentos e responsabilidades relativos ao controle e vigilância da qualidade da água. Disponível em: <http://dtr2004.saude.gov.br/dab/saudebucal/ legislacao/portaria518_25_03_04.pdf>. Acesso em: 23 nov 2017.

BRITO, L.T.L.; AMORIM, M.C.C.; LEITE, W.M. Qualidade de água para consumo humano. Petrolina: Embrapa Semi-Árido, p. 16, 2007.

BROMBERG, M. Safe drinking water: Microbial standards help ensure water quality for consumers. 1995. Disponivel em: < http://hermes.ecn.purdue.edu/cgi/convwqtest?/ru7.il.ascii >. Acesso em: 22 nov. 2017.

CABRAL, L.N.; ARAÚJO, S.M.S de. Qualidade da água em áreas rurais: análise bacteriológica e físicoquímica das águas dos tanques de pedra das comunidades KM 21 (Campina Grande) e Pedra Redonda. Revista Brasileira de Geografia Física v.09, n.06 (2016) 1737-1753.

CASALI, C.A. Qualidade da água para consumo humano ofertada em escolas e comunidades rurais da região central do Rio Grande Do Sul. 2008. 173 f. Dissertação (Mestrado) - Curso de Programa de Pósgraduação em Ciências do Solo, Centro de Ciências Rurais, Universidade Federal de Santa Maria, Santa Maria, 2008. Disponível em: <http://w3.ufsm.br/ppgcs/images/dissertacoes/carlosalbertocasali.pdf $>$. Acesso em: 9 jan. 2018.

COELHO, Silvio Carlos et al. Monitoramento da água de poços como estratégia de avaliação sanitária em Comunidade Rural na Cidade de São Luís, MA, Brasil. Rev. Ambient. Água, Taubaté, v. 12, n. 1, p. 156-167, Feb. 2017. 156-167, 2017.

\section{CONCEIÇÃO DAS ALAGOAS. CIDADE. Disponível em: < http://www.conceicaodasalagoas.mg.gov.br $>$. Acesso em 03 de jan de 2018.}

DI BERNARDO, L.; DANTAS, A. Di B. Métodos e técnicas de tratamento de água. vol. 1. 2. ed. São Carlos: RiMa, 2005. 
ESTEVES, C.C. O regime jurídico das águas minerais na Constituição de 1988. 2012. Tese (Doutorado) -Instituto de Geociências, Universidade Estadual de Campinas. Campinas, 2012.

FERREIRA, F. S.; QUEIROZ, T. M.; SILVA, T. V.; ANDRADE, A. C. O. À margem do rio e da sociedade: a qualidade da água em uma comunidade quilombola no estado de Mato Grosso. Saúde e Sociedade. São Paulo, v.26, n.3, p.822-828, 2017.

FRANCO, B.D. G.M.; LANDGRAF, F. M. Microbiologia dos alimentos. São Paulo: Atheneu, 1996. $52 \mathrm{p}$.

FUNASA. Manual de Saneamento. 3. ed. rev. Brasília: Fundação Nacional de Saúde, 2006.

FUNASA. Saneamento Rural. 2013. Disponível em : < http://www.funasa.gov.br/site/engenharia-desaude-publica-2/saneamento-rural/ $>$. Acesso em: 18 nov. 2017.

FUNDO DAS NAÇÕES UNIDAS PARA A INFÂNCIA (UNICEF). Sanitation and Hygiene: A Right for Every Child. Nova Iorque, 1999.

GOOGLE EARTH. Software livre, versão 7.1.5.1557. Disponível em: < https://earth.google.com/web/@-19.88900335, $48.2077722,0 \mathrm{a}, 5289.70740969 \mathrm{~d}, 35 \mathrm{y}, 0 \mathrm{~h}, 45 \mathrm{t}, 0 \mathrm{r} / \mathrm{data}=$ CkwaShJECiUweDk0YmIyNGZmZjNiNjQwYjk6M HhmNzIyYWRhYjEwNjUxOTliGeOFGb-

V4zPAIU0CikeYGkjAKglQb25jaWFub3MYAiABK

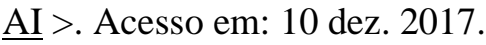

INSTITUTO ADOLFO LUTZ. Normas Analíticas do Instituto Adolfo Lutz. v. 1: Métodos químicos e físicos para análise de alimentos, 4. ed. São Paulo: IMESP, 2008.

INSTITUTO BRASILEIRO DE GEOGRAFIA E ESTATÍSTICA (IBGE). Censo Demográfico de 2010.

em:<http://www.sidra.ibge.gov.br/cd/cd2010

universo.aspo=7\&i=P>. Acesso em: 24 abr. 2018.

MARTEL, A. B. El agua. Calidad y tratamiento para consumo humano. Manual I, Plantas de Filtración Rápida. Lima: HPE/CEPIS/OPS. 597 p. 2004.

ORGANIZAÇÃO DAS NAÇÕES UNIDAS (ONU). Declaração da "ONU Água” para o Dia Mundial da Água 2010. Disponível em: < http://www.unwater.org/downloads/unw_wwd_state ment1.pdf>. Acesso em $04 \mathrm{dez} 2017$.
PATIAS, I.S.; MICHELON, L.; ROSA, F.P.; SOARES, L.B.; RESMIM, C.M.; TUSI, M.M. Análise físico-química e microbiológica de águas subterrâneas utilizadas no abastecimento de zonas rurais de Jaguari, Rio Grande do Sul, Brasil. PERSPECTIVA, Erechim, v. 40, n. 151, p. 73- 82, 2016.

PAULA, J.G.D.Q de. Sistema de abastecimento de água para consumo humano com ênfase no Município de Passos-MG. Monografia (graduação) Fundação de Ensino Superior de Passos, Universidade de Minas Gerais - Passos, 2008.

PAVANELLI, G. Eficiência de diferentes tipos de coagulantes na coagulação, floculação e sedimentação de água com cor ou turbidez elevada. Dissertação de Mestrado. Escolade Engenharia da Universidade de São Paulo - São Carlos, 2001. 216p.

PEÇANHA, MP; FREITAS, NP; LOURENÇO, R. W.; DONALISIO, M R; CORDEIRO, R; VEDOVATO, MA. Saúde e Meio Ambiente. In: André H. Rosa; Leonardo Fraceto; Viviane MoschiniCarlos. (Org.). Meio Ambiente e sutentabilidade. 1ed. Porto Alegre: Bookman, v. 1, p. 155-176. 2012.

PINTO, C.M.A.; ARAÚJO, N.A.; SILVA JÚNIOR, D.F. Diagnóstico Preliminar do Saneamento Rural na Comunidade de Engenho Velho no Município de João Pessoa/PB. Revista Ambiental. V.1, n. 1, p. 26 - 36, Jan/Mar, 2015.

RAMOS, C.N; BARROSO, L.S. Análise da qualidade da água de poços na localidade de Donana (Campos dos goytacazes): proposta para promover a alfabetização científica. 2013. 62 p. Trabalho de conclusão de curso (Licenciatura em química) - Instituto Federal de Educação, Ciência e Tecnologia Fluminense, Campos dos Goytacazes, 2014.

SILVA, S. R.; HELLER, L.; VALADARES, J. C.; CAIRNCROSS, S. O cuidado domiciliar com a água de consumo humano e suas implicações na saúde: percepções de moradores em Vitória (ES). Engenharia Sanitaria e Ambiental. v.14, n.4, p. 521532, 2009.

SILVA, D, A. ESTUdO FÍSICO-QUÍMICO E MICROBIOLÓGICO DE ÁGUAS DE POÇOS LOCALIZADOS NA ZONA RURAL DA CIDADE DE CARUARU-PE. 2017. 46 p. Trabalho de conclusão de curso (Bacharelado em Engenharia Ambiental) - Centro Universitário Tabosa de Almeida, Caruaru, 2017. 
SILVA, M. QUALIDADE DA ÁGUA DE ABASTECIMENTO E ASPECTOS SOCIAIS E COMPORTAMENTAIS DE SEUS CONSUMIDORES NO MUNICÍPIO DE MOSSORÓ/RN. 2017. 92 p. Dissertação (Mestrado em Ambiente) - UNIVERSIDADE FEDERAL RURAL DO SEMI-ÁRIDO, Mossoró, 2017.

SOUSA, C.R.N.A.; MATIAS, A.O.; SANTOS FILHO, F.C.; SARMENTO, R.G.; GOMES, M.F.C COSTA, M.F. Análise da qualidade da água de três propriedades rurais do município de Floriano-Piauí. Revista Brasileira de Agropecuária Sustentável (RBAS), v.9, n.2, p.17-23, junho, 2019

TOMINAGA, M.Y.; MIDIO, A.F. Exposição humana a trialometanos presentes em água tratada. Revista de Saúde Pública, v. 33, n. 4, p. 413-421, 1999.

TRATA BRASIL. Internações por doenças de veiculação hídrica no Brasil. Trata Brasil. Disponível em: $<$ http://www.tratabrasil.org.br/blog/2019/05/21/in ternacoes-de-doencas-por-veiculacao-hidrica-nobrasil/>. Acesso em: 09 junho. 2020.

UNITED NATIONS EDUCATIONAL, SCIENTIFIC, AND CULTURAL ORGANIZATION - UNESCO. Water for a sustainable world. Paris, 2015.

VON SPERLING, M. Introdução à qualidade das águas e ao tratamento de esgotos. 3. ed., Belo Horizonte: Departamento de Engenharia Sanitária e Ambiental; Universidade federal de Minas Gerais, 2005.

ZERWES, C.M.; SECCHI, M.I.; CALDERAN, T.B.; BORDOLI de., J.; TONETTO, J.F.; TOLDI, M.; OLIVEIRA, E.C.; SANTANA, E.R.R de. Análise da qualidade da água de poços artesianos do município de Imigrante, Vale do Taquari/RS. Ciência e Natura, v. 37, p. 651-663, 2015. 